\title{
Часть III
}

Государственное и муниципальное управление сквозь призму теорий мобильности и мягкой силы

УДК 321.7

DOI 10.17506/articles.mobility.2019.156169

Бабкин Александр Александрович, студент кафедры международных отношений, политологии и зарубежного регионоведения, Волгоградский государственный университет, г. Волгоград, E-mail: s4p4@yandex.ru

Федосеева Алина Алексеевна, студент кафедры международных отношений, политологии и зарубежного регионоведения, Волгоградский государственный университет, г. Волгоград,

E-mail: fedoseeva97_97@mail.ru

Панкратов Сергей Анатольевич, доктор политических наук, профессор, заведующий кафедрой международных отношений, политологии и регионоведения, Волгоградский государственный университет, г. Волгоград, E-mail: c.pankratov@mail.ru

\section{Тормоза мобильности или существующие проблемы электронного участия в Волгоградской области}

Статья посвящена исследованию состояния и перспективе развития электронного участия населения в Волгоградской области, раскрыты каналы, уровни и цели. Каналами выступают мобильные телефоны, персональные компьютеры, интерактивное телевидение. Представленными уровнями являются консультирование, информирование и активное участие, которые зависят от модели коммуникации. Первые два относят к типу взаимодействия «сверху вниз», последний предполагает характер интеракции между обществом и властными инсти- 
тутами «снизу-вверх». Целями служат вовлечение населения в дискуссию, информирование о политической ситуации и расширение возможностей граждан в определении актуальной политической повестки. Выявлены негативные факторы, влияющие на электронное участие граждан на региональном уровне. Определены наиболее популярные в Волгоградской области инструменты: два наименее интерактивных - опросы населения при использовании ИКТ и предоставление доступа к информации. Разработаны и представлены решения для существующих проблем, которые при реализации на практике имеют возможность повысить эффективность и популярность электронного участия не только в Волгоградской области, но и в других регионах. В качестве пунктов, разработанных авторами, выступают создание региональных интернет-представительств в социальных сетях, использование мессенджеров для коммуникации власти и граждан, практика внедрения мониторинга эффективности сервисов и предоставляемой информации, развитие и поддержание уже имеющихся электронных платформ и активное информирование о существующих возможностях взаимодействия с органами и представителями региональной власти. Данные меры направлены на расширение используемых каналов гражданами, выстраивание диалога с региональной властью, и популяризацию электронного участия. Авторы провели эмпирическое исследование, использовали метод экспертного опроса для подтверждения необходимости мониторинга и обновления существующих электронных ресурсов. Сделан вывод о том, что электронное участие в Волгоградской области находится на этапе развития и дальнейшие перспективы зависят от использования инструментария и готовности населения к применению электронных сервисов как канала коммуникации с властью.

Ключевые слова:

электронное участие, электронное правительство, электронная демократия, информационно-коммуникативные технологии, Интернет, социальные сети, мобильность.

Расширение пространства публичной коммуникации и увеличение возможностей взаимодействия гражданского общества и органов государственной власти на всех уровнях осуществляется благодаря активной интеграции и распростра- 
нению пользования сети Интернет в качестве канала связи. Его преимуществом является потенциальная возможность распространения демократического участия граждан в муниципальном и государственном управлении, которое повышает мобилизационные возможности населения.

В научном сообществе операционализация понятия электронного участия (ЭУ) имеет множественный подход. В этой работе под данным термином понимается процесс двусторонней коммуникации между представителями государственной власти на разных уровнях и гражданами с использованием сети Интернет. В более узком смысле исследователи раскрывают понятие электронного участия как набор конкретных методов, направленных на реализацию взаимодействия граждан и правительства. Итогом данной интеракции выступает принятие политического решения. К наиболее распространенным методам ЭУ относятся: консультации, информирование, публичные дискуссии и подача петиций [Демушина, 2015, с. 114]. В сфере электронного участия применяются информационнокоммуникационные технологии для привлечения различных социально-демографических групп общества в сферу публичной политики и развития новых каналов и форм взаимодействия с органами власти на всех уровнях.

Платформой реализации ЭУ граждан выступает сеть Интернет, доступ к которой может осуществляться через несколько каналов: мобильные телефоны, персональные компьютеры, интерактивное телевидение. По данным Организации Объединенных Наций электронное участие делится на три уровня, которые коррелируют со степенью вовлеченности граждан: консультирование, информирование и активное участие [Голубева, Ишматова, 2012, с. 54]. Представленные уровни соответствуют основным целям ЭУ - вовлечению населения в процесс дискуссии по социальным и политически значимым проблемам, распространению доступа и открытости к информации, расширению возможностей и прав граждан в определении актуальной повестки в рамках политической сферы. Анализируя цели электронного участия, стоит отметить, что первые две из них направлены на информирование населения о политической ситуации и обратную связь на действия правительства. Модель коммуникации в этом случае выстроена по принципу «сверхувниз». Третья цель предполагает инструменты и механизмы участия, которые построены на модели взаимодействия «снизувверх». Главный принцип данной модели в том, что граждане 
не только выступают в качестве потребителей, но и являются активными участниками в формировании политической повестки [Демушина, 2015, с. 115].

Анализ существующих отечественных сервисов электронного участия демонстрирует, что на данном этапе развития использование всех потенциально реализуемых инструментов не представляется возможным, поскольку институциональная и инфраструктурная ресурсная база для их обеспечения находится в стадии формирования. В этой связи на решение данной проблемы были направлены государственные программы «Информационное общество (2011-2020 годы)» [Постановление № 313, 2014] и «Цифровая экономика Российской Федерации» [Распоряжение № 1632-p, 2017], которые ставят одной из своих приоритетных целей создание благоприятных и стимулирующих условий для реализации позитивного преобразования существующей ситуации в сфере информационных технологий.

Исследования электронного участия на региональном уровне, проводимые на примере Волгоградской области, демонстрируют общероссийские тенденции, но в ходе изучения экспертного опроса была выявлена специфика практики реализации в регионе. При качественной оценке эксперты отмечают его удовлетворительным как на федеральном, так и на региональном уровнях. Стоит подчеркнуть, что $45 \%$ из опрошенных экспертов в данном исследовании считают, что по 5-балльной шкале 3 отражает реальность. Другая часть респондентов склоняется к наименее положительной оценке. Как один из главных тормозящих факторов развития выделяется низкая активность со стороны населения. По мнению экспертов, данный факт объясняется низкой компьютерной грамотностью части населения и сложностью представленных электронных платформ, а также недостаточной открытостью и прозрачностью власти. Исследователь отмечает, что главной задачей в ходе опроса было выяснить, есть ли у населения механизмы и возможности влиять на политическую ситуацию в регионе. Среди опрашиваемых государственных служащих $2 \%$ респондентов считают, что граждане должны выступать и инициировать электронные формы взаимодействия между обществом и властью, 24 \% выделяют общественные организации как активных акторов с инициативой к коммуникации, и $74 \%$ ответили, что побуждение должно исходить только от власти. Положительной тенденцией развития электронного участия в регионе мож- 
но отметить выражение заинтересованности местных властей к взаимодействию с населением - среди опрошенных чиновников Волгоградской области 78\% выразили возможность привлечения населения к обсуждению и решению региональных проблем, и только 9\% респондентов не считают необходимым привлечение граждан. В ходе опроса наиболее популярными в Волгоградской области инструментами электронного участия являются два наименее интерактивных - опросы населения при использовании ИКТ и предоставление доступа к информации. Для выстраивания двусторонней коммуникации с гражданами отдается предпочтение технически простым и традиционным средствам взаимодействия [Демушина, 2017, с. 134].

Концепция электронного участия граждан предполагает наличие двусторонней коммуникации и оперативной обратной связи со стороны государственного аппарата. Свойство мобильности и её уровень зависит от полноты используемых методов, механизмов и инструментов. На основе анализа использования данных технологий на государственном и региональном уровне в России следует вывод, что для развития мобильности государственного аппарата на всех уровнях необходимо устранение тормозящих факторов как со стороны государственного управления, так и со стороны социума.

Наше видение решения проблем мобильности ЭУ в Волгоградской области состоит в упрощении барьеров, которые представлены практиками старой коммуникации и фокусировании на практиках использования мобильных устройств. На фоне демонстрации активного распространения российской мобильной аудитории - по данным Mediascope на момент 2018 года доля пользователей мобильного Интернета составляет более 73 млн. человек, что представляет собой 59 процентов от всего населения страны старше 12 лет [Аудитория интернета ...] - есть основания предполагать, что высокая доля трафика на площадки электронного участия будет идти с мобильных устройств. На нынешнем этапе мы видим необходимыми следующие меры:

- создание сети интернет-представительств региональных институциональных организаций на платформах популярных социальных сетей в Российской Федерации. На настоящий момент социальные сети начинают занимать все большее место в жизни для россиян. Согласно сентябрьскому исследованию Mediascope «WEB-Index: Аудитория интернетпроектов», среднее количество российских пользователей со- 
циальной сети ВКонтакте только с десктопа составляет более 23 миллионов человек в месяц, Одноклассники и Facebook с теми же исходными данными представлены меньшей аудиторией - 12 и 11 миллионов, соответственно [WEB-Index ...]. Результаты исследования ВЦИОМ в начале 2018 года показали, что $45 \%$ опрошенных российских респондентов старше 18 лет пользуются одной из популярных социальных сетей практически каждый день, а $62 \%$ - хотя бы раз в неделю [ВЦИОМ ...]. И хотя можно отметить, что аудитории данных площадок частично могут пересекаться между собой, этот процент все равно представляется обширной группой населения страны, включенной в постоянное перераспределение информационных потоков. Стоит также отметить, что попытки поддержания социальных связей дистанционным общением и погружением в систему, в которой происходит процесс перманентного агрегирования и воспроизводства информационного контента, становятся неким якорем, удерживающим пользователей на платформе. Такая стимуляция концентрирования внимания пользователя на её внутреннем содержании воспрепятствует привычному пониманию серфинга Интернета, образуя при этом иную форму поведения - сёрфинга страниц социальных сетей. В этой связи представляется логичным довериться силам притяжения более массивного информационного объекта и начать с ним взаимодействовать. Создание представительств региональных институтов позволит частично аннигилировать пространственные барьеры коммуникации с населением, что в свою очередь имеет возможность способствовать развитию электронного участия в Волгоградской области. Реализация данного направления не должна быть ограничена отчетностью о проделанной работе на персональных страницах. Для преодоления преград электронного участия представляется необходимым использовать выделяемый площадками спектр функциональных возможностей двусторонней коммуникации с гражданами. Это не посты с закрытыми комментариями, а реальные механизмы, стимулирующие взаимную работу власти и общества.

- Внедрение практик использования популярных мессенджеров. Необходимо отметить, что сервисы электронной почты, имея более 20 лет истории, начинают морально устаревать и заменяться иными сервисами осуществления коммуникации, имеющими более упрощенную форму. В связи с развитием пользователей мобильных девайсов расширяется и база сер- 
висов мгновенной передачи сообщений. На момент 2018 года, по данным Mediascope, около 62 процентов россиян в возрасте от 12 до 64 лет хотя бы раз в месяц используют один из популярных мессенджеров, опережая при этом по показателю среднего количества дней использования в месяц социальные сети и сервисы электронной почты [ВЦИОМ ...]. Нынешний технологический функционал мессенджеров имеет возможность создания ботов, которые также могут осуществлять функции информирования, сбора и обработки данных, что становится выгодным как представителям власти, поскольку снижает транзакционные издержки на различные операции, так и гражданам, поскольку существует потенциал получения полезной оперативной информации. Еще один плюс использования инструментария социальных сетей и мессенджеров заключен в том, что порог понимания использования интерфейса сервиса электронного участия внутри данных площадок будет широк, исходя из ранее приобретенного на ней пользовательского опыта и его интуитивной понятности, и поэтому обучать граждан пользоваться новой услугой практически не нужно.

- Содействовать развитию уже готовых сервисов для оперативной подачи обращений и инициатив. Заинтересованность уже существующих сервисов электронного участия в развитии близких контактов с профильными представителями органов власти выражается в различных аспектах. В том числе в потенциальной возможности стать более эффективной площадкой за счёт сокращения временных и иных издержек при осуществлении совместной работы по решению конкретной проблематики, что в свою очередь может привести к росту популярности данного сервиса и повышению прибыли. В этом смысле также затрагивается вопрос возможности делегирования части собственных полномочий по тому же сбору обращений сторонним сервисам на аутсорсинг. Привлечение населения к двустороннему мониторингу процесса разрешения проблемы может повысить не только качество проводимых работ, но и доверие к подобным площадкам и властным институтам.

- Внедрить практики проведения регулярного мониторинга эффективности элементов предоставляемых сервисом услуг и их обновлений. Учитывая, что с момента публикации платформы в сети она имеет шансы существовать в статике до тех пор, пока не подвергнется внешнему влиянию - неполадки с сервером, истечение срока доменного имени, - необходимо отметить, что при постоянно проходящем процессе из- 
менения пользовательского поведения не все технические решения с течением времени могут быть актуальны и выдавать желаемый результат. Анализ современной российской практики показывает, что зачастую интернет-проекты, не направленные на получение прибыли, проводят обновление своих площадок менее регулярно, чем коммерческие проекты. Туманное видение получения каких-либо благ с подобных проектов естественным образом не стимулирует выделять финансирование на обеспечение развития данных ресурсов, что постепенно приводит к потере качества предоставляемой услуги и упадку пользователей. Для изучения данной практики мы провели собственный экспертный опрос, в рамках которого в выборку попали разработчики сайтов: дизайнеры, программисты, сеоспециалисты, иными словами, лица, которые непосредственно взаимодействуют с заказчиками подобных продуктов. В ходе исследования наиболее популярными ответами оказались следующие причины: чёткое представление заказчиков, что технически завершенный продукт не нуждается в доработке; обновление сайта представляется не технической реорганизацией отдельных элементов, а наполнением контентом; создание собственных площадок вызвано имиджевой характеристикой, а не реальной функциональной потребностью. Однако реальное функционирование площадок, подобно иным формам организации, в действительности требует развития. Именно в этой связи для обеспечения наиболее результативной работы институтов электронного участия в интернет-пространстве представляется необходимым адаптировать их под различные устройства, организовывать механизмы конвертации посетителей в пользователей, выявлять проблемные страницы и их причины, проводить A/B тестирование по отдельным элементам, оптимизировать их, а также собирать и учитывать предложения пользователей по улучшению сервиса.

- Усиление кампаний по информированию о существующих возможностях. Какими бы доступными, удобными, понятными сервисы ни были, без должного интереса к проблемам в городской среде, без существования открытого спектра коммуникационных каналов взаимодействия с местными представителями власти, без знания реальных возможностей осуществления локальных позитивных преобразований данными площадками граждане пользоваться не будут. Именно в этой связи не стоит ограничиваться выпуском электронного политико-социального продукта в сеть с надеждой, что 
со временем поисковая выдача приведет заинтересованных лиц. В этом смысле однодневный сюжет новостей на местном телеканале не является единственным верным выходом. Данный путь, хотя и предполагает процесс обращения к массовой аудитории, гражданам, которые проживают на территории региона и потенциально могут, при наличии необходимости, воспользоваться новым сервисом, не всегда может гарантировать реально высокого процента осведомленности и конверсии. Целевая аудитория подобных новостных программ естественным образом не полностью интегрирована в использование интернет-технологий в силу отсутствия у части потребителей телевизионного контента необходимых для использования сервиса девайсов, желания их приобретения и последующего освоения. И хотя современные телевизоры имеют возможность серфинга сети Интернет, что дает основание предположить возможный переход на сервис для детального ознакомления после просмотра новостного ролика, однако исследование GfK «Проникновение Интернета в России: итоги 2017 года» показало, что лишь 19 процентов опрошенных имеют дома телевизор с технологией Smart TV, из которых 48 процентов практически отказались от её использования, а оставшиеся 52 процента обращаются к ней нерегулярно [Исследование GfK ...]. Это дает нам возможность предположить, что подобное пользовательское поведение маловероятно, и ограничиваться только одним каналом коммуникации не стоит. Поскольку мы в основном говорим об интернет-пространстве, логичнее было бы взаимодействовать с его непосредственными пользователями. Ведь представляется естественным, что находясь на одной площадке, при грамотном описании его необходимости и упрощенной формой перехода от источника информации, количество уникальных посетителей, или, иначе говоря, потенциальных пользователей будет больше относительно иных классических каналов информирования. Именно поэтому стоит организовать совместную работу по информированию населения о появлении новой возможности не только с традиционными местными СМИ, которые представлены в Интернете, но и с популярными региональными блоггерами, иными словами различными лидерами мнений данных площадок, а также администраторами локальных сообществ. Эти меры позволят осуществить наиболее точечную коммуникацию с целевой аудиторией. Таким образом, для полноценной работы новых или уже существующих платформ электронного участия нам представляется необходимым 
осуществление работ по устранению проблемы недостаточной информированности граждан путем реализации комплексной рекламной кампании, которая не ограничивалась бы классическими источниками каналов коммуникации.

На основе изученных материалов и эмпирических исследований следует вывод, что электронное участие в Волгоградской области находится на этапе становления. На существующих электронных платформах функционируют и используются несколько видов инструментов, в основном позволяющих гражданам получить информацию и консультацию. Поддержание и прочное установление модели двусторонней коммуникации с представителями региональной власти пока не демонстрирует высокого уровня развития. Для дальнейшей популяризации электронного участия в Волгоградской области необходимо провести ряд мер, которые продемонстрируют населению положительные характеристики применения электронных платформ и сервисов.

\section{БИБЛИОГРАФИЧЕСКИЙ СПИСОК}

Аудитория интернета в России выросла на 4\% [Электронный ресурс]. URL: http://mediascope.net/press/news/812866/ (дата обращения: 29.10.2018).

ВЦИОМ: Каждому возрасту - свои сети [Электронный реcypc]. URL: https://wciom.ru/index.php?id=236\&uid=116691 (дата обращения: 29.10.2018).

Голубева А.А. Ишматова Д.Р. 2012. Электронная демократия в России: формирование традиций политической осведомленности и участия // Вопр. гос. и муницип. управления. № 4. С. 50-65.

Демушина О.Н. 2015. Электронное участие граждан как форма взаимодействия власти и общества // Карельский науч. журн. № 1. С. 114-117.

Демушина О.Н. 2017. Факторы повышения эффективности электронного участия граждан [Электронный ресурс] // Ars Administrandi. T. 9, № 2. C. 132-151. URL: https://cyberleninka. $\mathrm{ru} / \mathrm{article} / \mathrm{n} /$ faktory-povysheniya-effektivnosti-elektronnogouchastiya-grazhdan (дата обращения: 31.10.2018).

Исследование GfK: Проникновение Интернета в России [Электронный pecypc]. URL: https://www.gfk.com/ru/ insaity/press-release/issledovanie-gfk-proniknovenie-interneta-vrossii/ (дата обращения: 24.10.2018). 
WEB-Index: Аудитория интернет-проектов: Результаты исслед.: Desktop, Сентябрь 2018 [Электронный ресурc]. URL: http:// mediascope.net/services/media/media-audience/internet/informatio $\mathrm{n} /$ ?download $=2480 \&$ date $=2018 \% 2009 \&$ captcha code $=0$ ec 033 def 8 68f31e94e5d87e909d8d68\&arrFilter_pf [YEAR] $=2018 \&$ captcha word=S2X9G\&set_filter=Y (дата обращения: 29.10.2018).

Постановление Правительства Российской Федерации от 15 апреля 2014 г. № 313 (ред. от 25 сентября 2018) «Об утверждении государственной программы Российской Федерации «Информационное общество (2011-2020 годы)» [Электронный ресурc]. URL: http://www.consultant.ru/document/cons_doc_ LAW_162184/ (дата обращения: 30.10.2018).

Распоряжение Правительства Российской Федерации от 28 июля 2017 г. № 1632-р «Об утверждении программы «Цифровая экономика Российской Федерации» [Электронный pecypc]. URL: http://static.government.ru/media/files/9gFM4FHj4 PsB79I5v7yLVuPgu4bvR7M0.pdf (дата обращения: 30.10.2018).

\section{References}

Auditoriya interneta $v$ Rossii vyrosla na $4 \%$ [Internet audience in Russia grew by 4\%], available at: http://mediascope.net/press/ news/812866/ (accessed October 29, 2018). (in Russ.).

Demushina O.N. Elektronnoe uchastie grazhdan kak forma vaimodeystviya vlasti i obshchestva [Electronic citizen participation as a form of interaction between authorities and society], Karel'skiy nauchniy zhurnal, 2015, no. 1, pp. 114-117. (in Russ.).

Demushina O.N. Faktory povysheniya effektivnosti elektronnogo uchastiya grazhdan [Factors increasing the effectiveness of e-participation of citizens], Ars Administrandi, 2017, vol. 9, no. 2, pp. 132-151, available at: https://cyberleninka. $\mathrm{ru} /$ article/n/faktory-povysheniya-effektivnosti-elektronnogouchastiya-grazhdan (accessed October 31, 2018). (in Russ.).

Golubeva A.A. Ishmatova D.R. Elektronnaya demokratiya $v$ Rossii: formirovanie traditsiy politicheskoy osvedomlennosti $i$ uchastiya [Electronic democracy in Russia: setting up the tradition of political awareness and participation], Voprosi gosudarstvennogo i munitsipalnogo upravleniya, 2012, no. 4, pp. 50-65. (in Russ.).

Issledovanie GfK: Proniknovenie Interneta v Rossii [Research GfK: Internet penetration in Russia], available at: https:/www. 
gfk.com/ru/insaity/press-release/issledovanie-gfk-proniknovenieinterneta-v-rossii/ (accessed October 24, 2018). (in Russ.).

Postanovlenie Pravitel'stva Rossiyskoy Federatsii ot 15 aprelya 2014 g. № 313 (red. ot 25 sentyabrya 2018) "Ob utverzhdenii gosudarstvennoy programmy Rossiyskoy Federatsii "Informatsionnoe obshchestvo (2011-2020 gody)" [Resolution of the Government of the Russian Federation of April 15, 2014 No. 313 (as amended on September 25, 2018) "On approval of the state program of the Russian Federation" Information Society (2011-2020)"], available at: http://www.consultant. ru/document/cons_doc_LAW_162184/ (accessed October 30, 2018). (in Russ.).

Rasporyazhenie Pravitel'stva Rossiyskoy Federatsii ot 28 iyulya 2017 g. № 1632-r “Ob utverzhdenii programmy "Tsifrovaya ekonomika Rossiyskoy Federatsii" [Order of the Government of the Russian Federation of July 28, 2017 No. 1632-p "On approval of the program" Digital Economy of the Russian Federation"], available at: http://static.government. $\mathrm{ru} / \mathrm{media} /$ files/9gFM4FHj4PsB 79I5v7yLVuPgu4bvR7M0. pdf (accessed October 30, 2018). (in Russ.).

VTSIOM: Kazhdomu vozrastu - svoi seti [WCIOM: Every age has its own networks], available at: https://wciom.ru/index. php? $\mathrm{id}=236 \&$ uid=116691 (accessed October 29, 2018). (in Russ.).

WEB-Index: Auditoriya internet-proektov: Rezul taty issled.: Desktop, Sentyabr' 2018 [WEB-Index: The audience of Internet projects. Research results: Desktop, September 2018], available at: http://mediascope.net/services/media/media-audience/internet/ information $/$ ?download $=2480 \&$ date $=2018 \% 2009 \&$ captcha_cod $\mathrm{e}=0 \mathrm{ec} 033 \mathrm{def} 868 \mathrm{f} 31 \mathrm{e} 94 \mathrm{e} 5 \mathrm{~d} 87 \mathrm{e} 909 \mathrm{~d} 8 \mathrm{~d} 68 \&$ arrFilter_pf [YEAR] 2018\&captcha_word $=$ S2X9G\&set_filter $=$ Y (accessed October 29, 2018). (in Russ.).

Alexander A. Babkin, Student of the Department of International Relations, Political Science and Area Studies, Volgograd State University, Volgograd, E-mail: s4p4@yandex.ru 


\section{Alina A. Fedoseeva, Student of the Department of International Relations, Political Science and Area Studies, \\ Volgograd State University, Volgograd, E-mail: fedoseeva97_97@mail.ru \\ Sergey A. Pankratov, Doctor of Political Sciences, Professor, Head of the Department of International Relations, Political Science and Area Studies, \\ Volgograd State University, Volgograd, E-mail: c.pankratov@mail.ru}

\section{Mobility Brakes or Existing Problems of Electronic Participation in the Volgograd Region}

\section{Abstract}

The article is devoted to the study of the state and prospects of electronic participation development in the Volgograd region, disclosing channels, levels and goals of participation. The channels mentioned in the research are mobile phones, personal computers and interactive television; the levels are counselling, information and active participation, depending on the model of communication. The first two belong to the type of interaction "from top to bottom", the latter assumes the nature of interaction between society and power institutions "from bottom to top". The objectives are to involve the population in the discussion, to inform about the political situation and to empower citizens in determining the current political agenda. The negative factors influencing electronic participation of citizens at the regional level are also revealed.

The most popular instruments of electronic participation are identified: two of the least interactive-surveys of the population using ICT and providing access to information. Solutions for existing problems have been developed and presented, which, when implemented in practice not only in the Volgograd region, but also in other regions, have the opportunity to increase the efficiency and popularity of electronic participation. The points developed by the authors are to create the regional Internet offices in social networks; to use messengers for communication between government and citizens; to practice monitoring of the effectiveness of services 
and information provided; to develop and maintain existing electronic platforms and active information about opportunities for interaction with authorities or their representatives. It is concluded that electronic participation in the Volgograd region is at the stage of development and further prospects depend on the use of instruments available and the readiness of the population to use electronic services as a channel of communication with the authorities.

Keywords:

e-participation, e-government, e-democracy, information technology, internet, social media, mobility. 